\title{
Network Analysis Based the Trends in International Conference on Appropriate Technology (ICAT)
}

\author{
Jeeyoon Kwak ${ }^{1,2}$, Seongpil Jeong ${ }^{1,3, \dagger}$ \\ ${ }^{1}$ Water Cycle Research Center, Korea Institute of Science and Technology, 5, Hwarang-ro 14gil, \\ Seongbuk-gu, Seoul 02792, Republic of Korea \\ ${ }^{2}$ Department of Statistics and Information Science, Dongduk Women's University, 60 Hwarang-ro 13-gil, \\ Seongbuk-gu, Seoul 02748, Republic of Korea \\ ${ }^{3}$ Division of Energy \& Environment Technology, KIST School, Korea University of Science and Technology, \\ 5, Hwarang-ro 14gil, Seongbuk-gu, Seoul 02792, Republic of Korea
}

\author{
네트워크 분석 기반 적정기술국제학회의 최근 연구동향 분석 \\ 곽지윤 ${ }^{1,2}$, 정성필 ${ }^{1,3, \dagger}$ \\ 1한국과학기술연구원 물자원순환연구센터 \\ 2 동덕여자대학교 정보통계학과 \\ ${ }^{3}$ 과학기술연합대학원대학교 KIST 스쿨 에너지-환경 융합공학과
}

\begin{abstract}
적정기술연구 분야는 환경, 의료, 교육 및 에너지 등 다양한 주제를 포함하고 있다. 따라서, 한 분야의 연구자가 적정 기술 전체 분야에 대한 연구 동향을 파악하기에는 어려움이 있다. 소셜 네트워크 분석, 즉, 사회 연결망 분석은 네트 워크에 어떤 전체적인 연결관계가 있는지를 분석하여 특정 관계망을 보기 쉽게 시각화 하거나 인사이트를 도출할 수 있는 방법이다. 이 논문에서는 소셜 네트워크 분석을 적정기술학회에서 개최한 2017-2019년까지의 적정기술 국제학회 초록집 자료를 이용하여 적정기술 분야의 학술 동향을 파악하고자 하였다. 적정기술학회에서 확보한 자료를 바탕으로 데이터 전처리 과정을 거쳐 공저자 네트워크를 분석하고 그와 관련된 통계적 지표를 해석하였다. 또한, 적정기술학회 의 일반 현황 자료를 기반으로 연차별 발표자 및 연구 내용 변화를 분석하고 결과를 도출하였다.

The research topics of the appropriate technology include environment, medical, education, and energy etc. Therefore, having a review on appropriate technology requires huge efforts of specialists from many difference research areas. Social network analysis has been applied to understand the relationships among the components in the network and to provide insights by visualizing the huge network having many components. In this study, the co-authors and their research topics at the international conference on appropriate technology (ICAT) held by Academic Society for Appropriate Technology (ASAT) from 2017 to 2019 were analyzed using the statistical and visualization tools. The networks between co-authors were analyzed using the pretreated data which were collected from ASAT. The annual trend or characteristics of the general information on ICAT were also analyzed.
\end{abstract}

KEYWORDS: International conference on appropriate technology, Network analysis, Research trend, Visualization

\footnotetext{
${ }^{\dagger}$ To whom correspondence should be addressed.

E-mail: spjeong@kist.re.kr

Received: 03 February 2021, Revised: 22 March 2021,

Accepted: 30 March 2021
} 


\section{Introduction}

경제적으로 취약한 개발도상국 수요자를 대상으로 하는 적정기술의 경우, 다양한 정부, $\mathrm{NGO}$, 기업, 종교 단체, 개 인 등이 적정기술 활동에 다양하게 참여하고 있으며, 현지 에 기술 보급, 보건 확충 및 교육 등 활동 방법 역시 다양 하다. 따라서, 적정기술 분야의 경우 하나의 학과 또는 분 야에서 총괄하여 이해하기 어려운 점이 있으며, 각 분야 및 주체들이 각자 적정기술활동을 수행하는 결과로서 보고되 는 특징이 있다. Shin 등은 라오스 지역을 중심으로 적용될 수 있는 적정 기술 예시를 제시한 바 있으며(Shin et al., 2019), 적정 기술과 적정 기술 정책의 연관성(Garniati et al., 2014) 또는 적정기술의 수용성(Boakye-Ansah et al., 2020) 에 대한 연구들이 수행된 바 있었다.

따라서, 다학제적 특징을 갖는 적정기술 활동의 연구 동 향을 파악하기 위해서는 과학기술 $\mathrm{ODA}$ 를 포함하는 다양 한 적정기술 활동들에 대하여, 출판된 다양한 연구자료들 을 바탕으로 하여 포괄적으로 연구 경향을 확인할 필요가 있다. 적정기술 전체의 특징을 파악하기 위한 연구 중 하나 로, Bauer와 Brown는 적정기술의 적정성을 평가할 수 있는 49 개 지표의 숫자의 발생 빈도에 대한 분석을 수행하였으 며, community input과 affordability가 적정기술 관련 논문 에서 자주 발견되는 것을 확인하였다(Bauer and Brown, 2014).

최근 들어, 분야별로 발표된 논문들의 주제, 초록 및 키 워드 등에서 주요 관련 용어를 추출하거나, 각 논문들의 저 자, 소속 등의 정보를 활용하여 연구 동향을 파악하는 네트 워크 분석 연구들이 수행되고 있다. Zhang 등과 Akbari 등 의 경우 지속가능한 기술 혁신(Sustainable Technology Innovation, STI)에 대한 연구 경향에 대하여 주요 인용 논 문, 공인용(co-citation) 분석 연구를 수행하여 주요 연구 주 제 등을 파악하였다(Zhang et al., 2020, Akbari et al., 2020).

이 연구들은 계량서지적 분석(bibliometric analysis) 방법 론을 활용하고 있다. 계량서지적 분석 관련 논문들은 2004 년 이전에는 매년 30-70건 정도 게재되었으나, 2005년(112 건) 이후 지속적으로 증가하여 2019년에는 년간 1,084 건의 논문이 게재되었다 (http://www. sciencedirect.com). 계량서 지적 분석을 이용하여 다양한 전문 주제에 대하여 논문이 출판되고 있으나, 아직까지 적정기술분야에 대해서는 국내 외에 출판된 적이 없으며, 적정기술 분야 다양한 논문들에 대한 네트워크 분석도 수행된 바가 없었다. 이는 적정기술 의 범위를 정하기 어려운 부분이 있기 때문인 것으로 사료 되며, 또한, 개별기술이 아닌 적정기술 분야 자체를 다루는 전문 연구가 없기 때문인 것으로 판단된다.
2018년 기준으로 국내 과학기술 ODA의 예산은 약 3조원 대로 국가 예산 중 상당한 비율을 갖고 있으며, 국내 GNI 증가에 따라 지속 증가되는 것을 목표로 하고 있다(정성필 등, 2018). 따라서, 우리나라의 적정기술 활동의 현황을 파 악하고 향후 발전 방향을 미리 확인하는 것은 중요한 일이 라고 사료된다. 이 연구에서는 2010년부터 11회째 개최된 바 있는 적정기술국제학회의 2017-2019년 발표 자료와 일 반 현황 자료 들을 바탕으로 하여 일반 현황 분석, 공저자 에 대한 네트워크 분석, 주제별 변화 분석 및 각 주제별 협 력 방식에 대한 분석을 통하여, 최근 우리나라에서 추진되 었던 적정기술 연구 동향을 파악하고, 계량서지적 분석법 을 다학제적 특성을 가진 적정기술 연구 분야에 적용하고 자 하였다.

\section{Materials and Methods}

\section{1. 데이터 수집}

적정기술국제학회 2017, 2018, 2019년의 초록집 자료를 바탕으로 발표저자 네트워크 분석을 위해 저자, 논문 제목, 소속 등의 변수를 추출하였다. 또한, 학회 초록집에서 얻을 수 없는 학회 일반 현황에 대하여서는 적정기술학회에 요 청하여 자료를 확보하였다.

적정기술국제학회의 경우 2010년부터 개최되었으나, 2016년까지 자료는 공저자에 대한 정보가 제공되어 있지 않거나, 초록집 형태로 남아있지 않아 통합된 분석을 수행 할 수 없어 초록집 형태로 존재하는 최근 2017-2019년 자 료만을 활용하여 분석을 수행하였다.

\section{2. 데이터 전처리}

데이터의 전처리는 자료 기반 연구에서 반드시 수행되어 야 할 기본 과정이다. 원 자료가 다양한 정보를 가지고 있 다면, 그 중에서 분석에 필요한 일부 자료들을 선택적으로 확보할 필요가 있다. 이 연구에서 데이터 전처리를 위하여 python 프로그램을 이용하였다.

2017년과 2018-2019년 초록집의 구성이 다르기 때문에 각 연도별 전처리를 다르게 적용하였다.

\section{1) 2018-2019년 초록집 자료의 전처리}

2019년 초록집은 한 세션 안에 세션 번호, 세션 제목, 좌 장, 발표 시간, 발표주제, 발표저자로 구성되어 있다(Figure 1). 규칙적으로 나열되는 텍스트 데이터를 변수화 하기 위 해 먼저 가장 큰 단위인 세션을 분할하였다. 발표에 참여한 사람 중 발표저자 만을 추출하기 위해 총 13 개의 세션에서 발표저자가 포함되지 않은 1 개의 세션을 제거하였다. 또한 
, 좌장, 패널토론, 패널토의, 종합토론, 사회 등의 항목을 제 거하여 발표저자 추출을 위한 데이터 제거를 완료하였다. 세션 번호와 세션 제목을 한 단위로 처리하여 각 세션 속 의 발표주제와 발표저자, 소속을 추출하였다. 발표 번호를 표기하기 위한 'OP' 다음 줄에 발표 주제가 있고, 다음 ' $\mathrm{OP}$ ' 가 나오기 전 '()'을 포함한 행은 발표 저자와 소속을 담고 있다.

발표 주제: 발표 시간과 발표 번호('OP')다음 줄에 항상 표기되어 있음

발표 저자: 발표 주제 다음 줄에 첫번째 글자와 '(' 앞의 글자 사이를 추출함

저자 소속: 괄호('()') 속에 들어있는 텍스트를 소속으로 처리

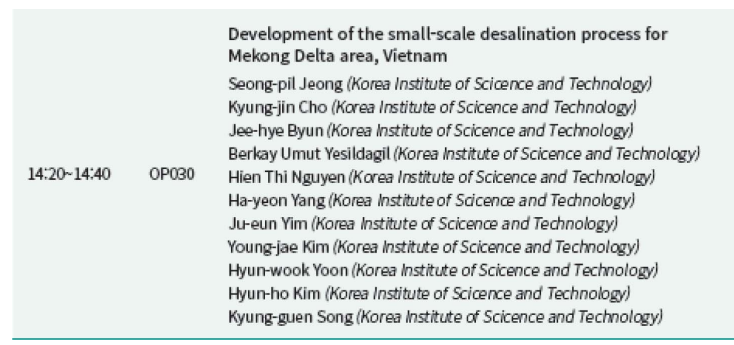

Figure 1. Example of the proceedings on ICAT 2019

\section{2) 2017년 초록집 자료의 전처리}

2017년 초록집은 2018-2019년의 초록집과 다르게 세션별, 발표순서별로 정리된 순서표에 발표저자 모두가 명시되지 않았다. 또한, 변수 추출을 자동화하기에는 텍스트에 일정 한 규칙이 없었기 때문에 순서를 부여하는 작업을 먼저 시 행하였다. 먼저 각 발표의 초록을 참고하여 모든 발표저자 와 발표주제를 추출하였다. 발표 주제의 행에는 '-'을 추가 하여 발표 단위로 전처리를 진행하였다. 발표 주제 다음 행 에는 각 저자의 소속 번호가 부여되어 있기 때문에 저자와 소속을 매칭하였다(Figure 2). 결과적으로 발표주제, 발표저 자, 소속을 모두 추출하였다.

\section{적정기술의 대학교육 커리큘럼 및 교재 개발}

신관우 ${ }^{1}$, 이충훈', 이원구1, 신선경',

김준원 ${ }^{3}$, 윤제용 ${ }^{4}$, 박형동 ${ }^{4}$, 이민화 '서강대학교, ${ }^{2}$ 한국기술교육대학, ${ }^{3}$ 포항공과대학교, ${ }^{4}$ 서울대학교, ${ }^{5}$ 도서출판 7 분의 언덕

Figure 2. Example of the proceedings on ICAT 2017

\section{3. 전처리된 자료를 이용한 연도별 저자, 소속 및 발표수 변 화 분석}

수집된 발표 저자, 소속 및 발표 자료를 바탕으로 각 연 도별 저자 수, 소속 수, 발표 수를 도출하였다. 특히 발표 수 중에서 2개 소속 이상의 발표자들로 구성된 발표를 '공동 연구’로 보고 공동연구의 수를 따로 표기하였다. 또한, 각 발표 별 평균 저자 수 $\left(\mathrm{N}_{\text {avg.author }}\right)$ 와 소속 별 평균 발표 수 $\left(\mathrm{N}_{\mathrm{avg} . \text { presentation}}\right)$ 를 아래 식으로 계산하였다. 또한, 대학생 또 는 중고등학생이 발표에 참여하는 적정기술학회의 특징을 반영하여, 학생발표 $\left(\mathrm{N}_{\text {student author }}\right)$ 로 구분하여 따로 분석을 수행하였다.

$$
\begin{aligned}
& N_{\text {avg.author }}=N_{\text {author }} / N_{\text {presentation }} \\
& N_{\text {avg.presentation }}=N_{\text {presentation }} / N_{\text {affiliation }} \\
& N_{\text {author }=} N_{\text {Total author }}-N_{\text {student author }} \\
& N_{\text {presentation }}=N_{\text {Total presentation }-} N_{\text {student presentation }} \\
& N_{\text {affiliation }}=N_{\text {Total affiliation }-N_{\text {student affiliation }}}
\end{aligned}
$$

\section{4. 데이터 기반 네트워크 시각화}

발표 저자 간의 관계를 시각화하기 위해 이름, 소속, 발 표제목으로 구성된 데이터 프레임을 노드(node, 사람)와 엣 지(edge, 관계)로 나누어 엑셀 파일을 생성하였다. 데이터 기반 네트워크 시각화를 위하여 Gephi 프로그램을 이용하 였다.

노드(사람)는 이름과 소속이 담긴 파일로 구성하였다. 시 각화를 위해 사용할 프로그램인 Gephi 프로그램에서는 사 람을 이름으로 인식하지 않고 고유번호로 인식하기 때문에 각 발표저자에게 고유 번호를 부여하여 결과적으로 이름 (Label), 고유번호(ID), 소속(Belong), 소속번호 (Belong_id) 변수로 노드의 파일을 생성하였다.

엣지(관계)는 같은 발표주제로 발표한 발표저자 간의 네 트워크를 표시하기 위해 조합을 활용하여 교류 가능한 모 든 경우의 수를 포함하였다. 노드와 마찬가지로 사람과 사 람 간의 관계는 이름이 아닌 고유 번호로 표기하였다. 그리 하여 엣지는 사람1 (Source), 사람2(Target), 발표주제(Title) 변수로 구성하였다.

\section{5. 네트워크 시각화 자료 기반 학회 특성 분석}

작성된 2017-2019년 네트워크 분석 자료를 활용하여 각 연구 별 2개 이상의 기관으로 구성된 공동연구 그룹을 파 악하였으며, 해당 공동연구 그룹별 연구 주제를 확인하였 다. 공동 연구된 전체자료를 구분하기 위하여, 공통적인 연 구주제로 쓰일 수 있는 큰 주제인 물/환경, 적정기술센터 관 
련, 의료, 에너지, 교육, ICT, 농업, 리빙랩, 항공우주, 도시 /주거, 기후변화, 로봇 및 학생 발표로 임의 구분하였다.

확인된 연구 주제는 각 해당 연차별로 주제별 자료로 정 리되었으며, 공동 연구의 형태(국내 기관 또는 해외 현지 기 관 등)도 파악하였다. 특히, 한국 내 협력과 한국과 개도국 및 미국과의 공동 연구로 크게 구분하였으며, 상세 주체를 연구 그룹(대학 및 연구소), 기업, 학생 및 정부로 구분하여 분석을 수행하였다.

\section{Results and Discussion}

\section{1. 적정기술국제학회 일반 현황 분석}

2017-2019 기간 동안 학회 일반 현황에 대하여 아래 표 (Table 1)로 정리하였다.

서울대, 한양대, 한국과학기술연구원 (KIST)에서 '4차 사 업혁명 시대 속의 적정기술의 역할', '포용과 나눔의 과학 기술' 및 '과학기술을 통한 지역 공동 번영'이라는 주제로

Table 1. Summarized general information for the international conferences on appropriate technology (2017-2019)

\begin{tabular}{|c|c|c|c|}
\hline & $2017\left(8^{\text {th }}\right)$ & $2018\left(9^{\text {th }}\right)$ & $2019\left(10^{\text {th }}\right)$ \\
\hline $\begin{array}{l}\text { Conference } \\
\text { venue }\end{array}$ & $\begin{array}{c}\text { Seoul } \\
\text { National } \\
\text { University }\end{array}$ & $\begin{array}{l}\text { Hanyang } \\
\text { University }\end{array}$ & $\begin{array}{c}\text { Korea } \\
\text { Institute of } \\
\text { Science and } \\
\text { Technology }\end{array}$ \\
\hline $\begin{array}{l}\text { Main subject } \\
\text { of the } \\
\text { conference }\end{array}$ & $\begin{array}{l}\text { The role of } \\
\text { appropriate } \\
\text { technology } \\
\text { in the Era } \\
\text { of the } 4^{\text {th }} \\
\text { industrial } \\
\text { revolution }\end{array}$ & $\begin{array}{l}\text { Science \& } \\
\text { technology } \\
\text { for } \\
\text { engagement } \\
\text { and sharing }\end{array}$ & $\begin{array}{l}\text { Regional } \\
\text { common } \\
\text { prosperity by } \\
\text { science and } \\
\text { technology }\end{array}$ \\
\hline $\begin{array}{l}\text { The number } \\
\text { of organizers }\end{array}$ & 10 & 12 & 15 \\
\hline $\begin{array}{l}\text { The number } \\
\text { of the invited } \\
\text { speakers and } \\
\text { debaters }\end{array}$ & 115 & 130 & 103 \\
\hline $\begin{array}{l}\text { The number } \\
\text { of academic } \\
\text { sessions }\end{array}$ & 8 & 10 & 13 \\
\hline $\begin{array}{l}\text { Student } \\
\text { program }\end{array}$ & Included & Included & Excluded \\
\hline $\begin{array}{l}\text { The number } \\
\text { of total } \\
\text { participants }\end{array}$ & 800 & 500 & 420 \\
\hline
\end{tabular}

학회가 개최되었다. 2017-2019년 동안 학회를 공동 주관하 는 단체가 지속적으로 증가하였으며, 이는 적정기술 학회 와 관련한 단체들이 적정기술국제 학회로 모이고 있다는 점을 시사한다. 또한, 학회의 구성적인 측면에서도 세션의 숫자가 증가된 점을 바탕으로, 다학제적이고 융합적인 적정 기술 분야의 특징이 강화되고 있을 수 있다고 판단된다. 총 참석자 수는 감소하고 있는 추세로 보이나, 2019년에는 학 생활동이 학회행사와 따로 추진된 점이 있어 향후 지속적 인 참석자에 대한 조사가 필요할 것으로 판단된다.

\section{2. 적정기술국제학회 네트워크 시각화 기반 공저자 분석}

\section{1 각 연도별 연도별 저자, 소속 및 발표수 변화 분석}

수집된 발표 저자, 소속 및 발표 자료를 바탕으로 각 연 도별 저자 수, 소속 수, 발표 수를 도출한 뒤 저자 분석을 수행하여 아래 Table 2를 작성하였다. 2017년에서 2019년까 지 발표 별 평균 저자 수는 증가하는 추세를 보이고 소속 별 평균 발표 수는 감소하는 경향을 보인다. 이는 발표의 개 수가 점점 줄어듦에 따라 발표 별 평균 저자의 수는 증가 하고, 감소하는 발표의 수와 더불어 소속의 개수는 점점 증 가하기 때문에 소속 별 평균 발표 수는 감소하게 된다. 또 한, 공동연구 개수는 평균 16 건으로 연도 간 큰 차이를 보 이지 않았으나, 연도별 공동 연구의 비율은 2017년은 $23.6 \%, 2018$ 년은 $16.2 \%$ 2019년은 $26.2 \%$ 으로 2018년에 상 대적으로 낮게 나타났다.

2017년부터 2019년까지 전체 발표 저자 수(학생 저자 수), 전체 소속 수(학생 소속 수), 및 전체 발표 수(학생 발표 수) 는 각각 평균 232(34) 명, 76(7)개, 및 79(8)건이었으며, 2018 년에 가장 많은 발표 저자 수, 소속 수 및 발표 수가 나타 났다. 중- 고등학교 학생들의 발표의 경우는 총 개수에는 포 함하였으나, 학술대회의 특징을 파악하기 위하여 계산한 발표 별 평균 저자 수, 소속 별 평균 발표 수, 공동 연구 및 이후 분석에는 활용하지 않았다.

\section{2 각 연별 네트워크 시각화}

전처리된 데이터베이스를 바탕으로 적정기술국제학회에 서 수행된 연도별 학술활동의 네트워크 시각화 결과를 아 래 Figure 3에 도시하였다.

Figure 3(a), (b) 및 (c)는 2017, 2018 및 2019년의 발표를 시각화하여 나타낸 것이다. 점(노드)은 발표자에 해당하고 같은 발표를 수행하는 경우 선(엣지)으로 연결되고 각 색깔 은 소속을 나타낸다. 군집의 개수가 발표 숫자를 의미하는 것은 아니며, 한 군집안에 여러 발표가 있을 수 있다. 
Table 2. Annual summary in the number of authors, affiliations and presentations

\begin{tabular}{|c|c|c|c|c|c|c|}
\hline Year & $\begin{array}{c}\mathrm{N}_{\text {Total author }} \\
\left(\mathrm{N}_{\text {student }}\right. \\
\text { author })\end{array}$ & $\begin{array}{c}\mathrm{N}_{\text {Total affiliation }} \\
\left(\mathrm{N}_{\text {student }}\right. \\
\text { affiliation }) \\
\end{array}$ & $\begin{array}{c}\mathrm{N}_{\text {Total presentation }} \\
\left(\mathrm{N}_{\text {student presentation }}\right)\end{array}$ & $\begin{array}{c}\mathrm{N}_{\text {Total research }} \\
\text { collaboration }\left(\mathrm{N}_{\text {student }}\right. \\
\text { research collaboration })\end{array}$ & $\mathrm{N}_{\text {avg.author }}$ * & $\mathrm{N}_{\text {avg.presentation }} * *$ \\
\hline 2017 & $\begin{array}{l}218 \\
(26)\end{array}$ & $\begin{array}{l}70 \\
(8)\end{array}$ & $\begin{array}{l}81 \\
(9)\end{array}$ & $\begin{array}{l}22 \\
(1)\end{array}$ & 2.67 & 1.26 \\
\hline 2018 & $\begin{array}{l}284 \\
(62)\end{array}$ & $\begin{array}{c}84 \\
(10)\end{array}$ & $\begin{array}{c}91 \\
(13)\end{array}$ & $\begin{array}{l}19 \\
(0)\end{array}$ & 2.85 & 1.05 \\
\hline 2019 & $\begin{array}{l}196 \\
(14)\end{array}$ & $\begin{array}{l}75 \\
(2)\end{array}$ & $\begin{array}{l}64 \\
(3)\end{array}$ & $\begin{array}{l}15 \\
(1)\end{array}$ & 2.98 & 0.84 \\
\hline
\end{tabular}

$* \mathrm{~N}_{\text {avg.author }}=\mathrm{N}_{\text {author }} / \mathrm{N}_{\text {presentation }}$
$* * \mathrm{~N}_{\text {avg.presentation }}=\mathrm{N}_{\text {presentation }} / \mathrm{N}_{\text {affiliation }}$
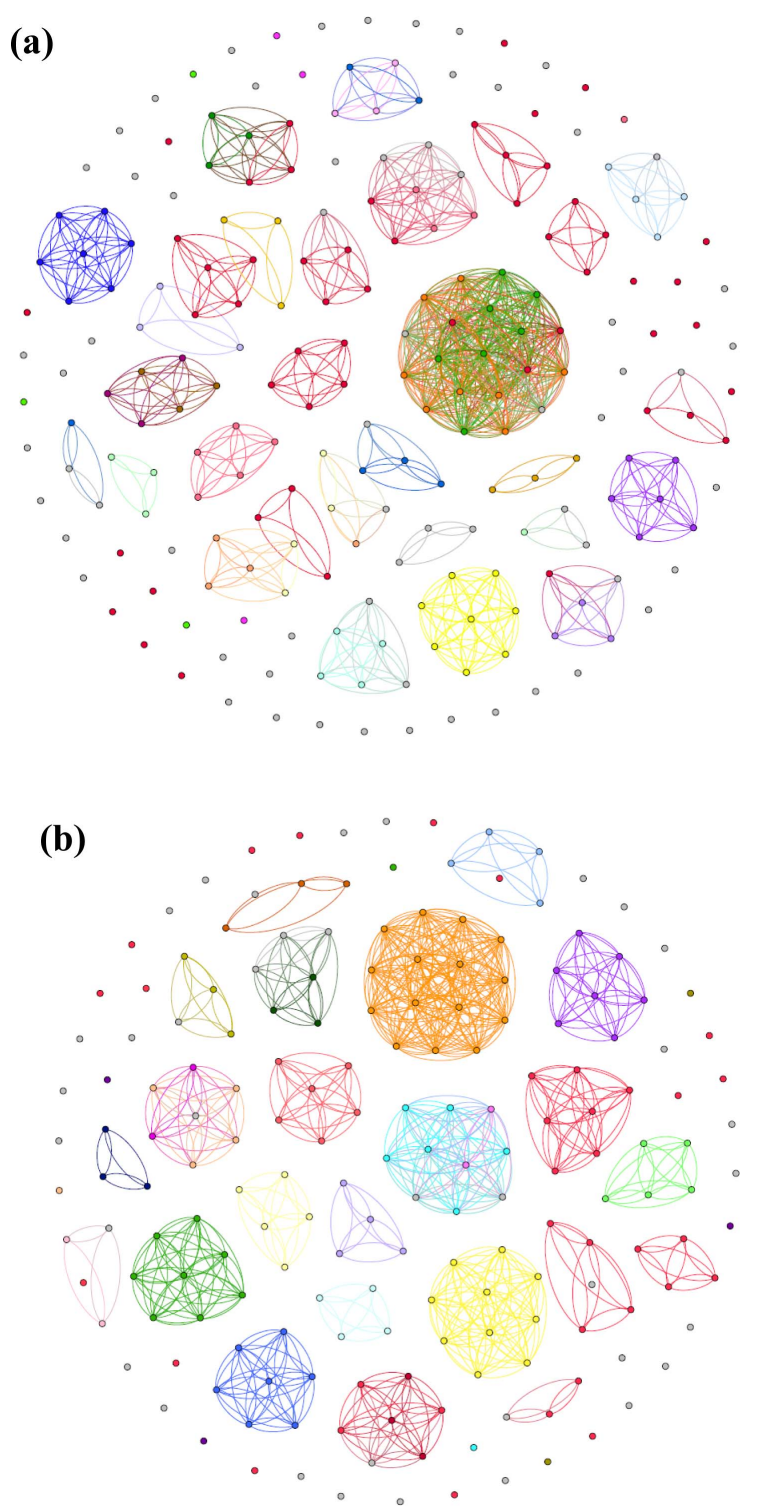

(c)

Figure 3. Annual visualization results of co-author networks ((a) 2017, (b) 2018, (c) 2019)

즉, 점이 선으로 연결된 경우가 공동 발표를 수행한 경우 를 의미한다. 또한, 다른 색깔의 점이 연결된 경우가 다른 소속의 연구자들이 공동연구를 수행한 경우를 의미한다. 예를 들어, 2017년의 경우(Figure 3(a)), 가장 큰 군집이면서 다수의 색을 가진 그룹이 존재하는데, 그 경우는 23 명의 연 구자가 참여한 "Electrification of Alpine Villages in Nepal" 발표였다. 이 발표에서는 서울대, 경상대, 한양대, 및 World Changers, Korea 소속의 연구자가 참여하였다. 2018년과 2019년의 경우에도(Figure 3(b-c)), 다수의 연구자들이 공동 연구를 수행한 것으로 나타났으며, 그에 대한 상세한 분석 은 뒤 챕터 3.3 에 설명하였다.

같은 색의 점이 모인 경우는 동일 소속이면서 다수의 연 구자가 참여한 경우를 의미한다. 따라서, 다수 기관에 의한 공동연구를 파악하는 것은 같은 그룹으로 묶여 있는 다른 
색깔점이 포함된 경우를 세는 방식으로 간단히 구할 수 있 었다. 이 연구에서는 3 개 연도의 자료를 사용하였기 때문에 직접 자료를 읽고 공동연구 숫자를 파악하는 것도 간단할 수 있으나. 향후 많은 연구 자료를 바탕으로 공동 연구의 숫 자를 파악하는데 있어서는 이런 방법론이 더 의미를 가질 것으로 판단된다.

시각화 연구에서 일반적으로 연구 내용을 바탕으로 연결 성을 파악하거나, 주요 연구 키워드를 도출하는 연구가 진 행되고 있으나, 이 연구에서는 연구 논문 전체가 아닌, 학 술발표 초록집에 제시된 공저자를 파악하는 기초 자료로서 한정적으로 네트워크 분석을 수행하였다.

시각화를 통하여, 전체 연구자들 중에서 공동 연구자로 군집화 된 부분을 쉽게 파악할 수 있었고, 특히, 2 개 기관 이상의 연구자가 함께 연구를 수행한 경우를 쉽게 확인할 수 있었다. 시각화 자료에서 드러난 2 개 기관 이상의 공동 연구에 대하여 다음 챕터에서 연도별 특징을 추가적으로 파악하여 보았다.

\section{3 각 연도별 네트워크 통계적 지표 해석}

Table 3에 나타난 세 가지의 지표의 증감을 통해 연도별로 변화하는 네트워크의 특성을 수치화하여 해석할 수 있다.

Table 3. Statistical indexes for co-author networks

\begin{tabular}{|c|c|c|c|}
\hline & Average degree & Graph density & Modularity \\
\hline 2017 & 4.202 & 0.019 & 0.809 \\
\hline 2018 & 4.049 & 0.014 & 0.938 \\
\hline 2019 & 3.364 & 0.017 & 0.935 \\
\hline
\end{tabular}

Average degree는 한 사람이 가지는 평균 관계의 개수를 의미한다. 연도가 지남에 따라 Average degree는 점점 낮아 지는 양상을 보이므로 논문 저자 간의 관계성이 줄어든다 고 볼 수 있다. Graph density는 네트워크가 얼마나 유효하 고 효과적인지를 알 수 있게 하는 하나의 척도로, 나올 수 있는 모든 관계의 개수와 실제 관계의 수의 비이다. Graph density도 Average degree 와 같이 연도가 지나면서 줄어드 는 양상을 보이는 것으로 보아 네트워크에 속한 인물들 간 의 연관성이 줄어들고 있다는 증거가 될 수 있다. 마지막으 로 Modularity는 전체 네트워크 안에 서로 유사한 특성을 가진 노드의 정도를 수치화한 값이다. 모듈성이 높을수록 같은 집단으로 분류된다. 지표에 사용된 저자의 특성은 소 속이고, 연도가 지남에 따라 점점 증가하는 양상은 같은 소 속끼리 논문을 진행할 가능성이 높아지고 있다고 해석할 수 있다.

\section{3. 네트워크 시각화 자료 기반 학회 특성 분석 결과}

네트워크 시각화 자료에서 2 개 이상의 연구기관이 참여 하는 공동연구로 표시된 그룹 자료를 기반으로 하여 연도 별, 연구분야별로 공동 연구 개수를 확인하여 아래 Table 4 에 나타내었다. 공동 연구 개수 도출 방법은 확보된 $\mathrm{DB}$ 에 서 발표 논문 제목(title)로 정렬한 뒤, 소속(belong)값이 다 른 것들의 개수를 세어 확보하였다.

Table 4에서 볼 수 있듯이, 수처리-환경 분야가 가장 많은 공동 연구가 추진되고 있음을 확인할 수 있었으며, 적정기 술거점센터(AT center), 의료, 에너지, 교육, ICT, 농업 등의 순으로 많은 공동 연구가 추진되고 있음을 확인할 수 있었 다. 그리고 연도별로 비슷한 숫자의 공동 연구들이 수행되 고 있음을 확인할 수 있었다.

Table 4. The number of collaborative researches according to the research areas

\begin{tabular}{ccccc}
\hline & 2017 & 2018 & 2019 & Total \\
\hline W-E* & 4 & 5 & 3 & 12 \\
AT** center & 3 & 3 & 1 & 7 \\
Medical & 2 & 2 & 2 & 6 \\
Energy & 2 & 3 & & 5 \\
Education & 3 & 2 & & 5 \\
ICT & 2 & 1 & 2 & 5 \\
Agriculture & 3 & & 1 & 4 \\
Living Lab. & & 1 & 2 & 3 \\
Aerospace & & 1 & 1 & 2 \\
Urban/housing & 1 & 1 & & 2 \\
Climate change & 1 & & 1 & 2 \\
Robot & & & 1 & 1 \\
Student & 1 & & 1 & 2 \\
\hline Total & 22 & 19 & 15 & 56 \\
\hline
\end{tabular}

W-E* (water-environment)

$\mathrm{AT}^{* *}$ (appropriate technology)

공동 연구를 추진하는 주체들은 연구기관(대학 또는 연 구소), 기업, 정부(지자체), $\mathrm{NGO}$, 학생으로 구분될 수 있었 으며, 각 연도별로 공동 연구의 형태를 Table 5에 정리하여 보았다.

총 56 건의 공동 연구 중에서 한국 그룹들 간의 공동 연 구 추진 횟수가 41건으로 가장 많았으며, 다음으로 한국 그 룹과 개발도상국 현지그룹과 연구 추진 횟수가 14회를 차 
Table 5. Collaborative researches according to the working groups in Korea (K), developing countries (D) and USA (A) (RE: research groups (university and research institute), EN: enterprise, ST: student, and GOV: government).

\begin{tabular}{|c|c|c|c|c|c|c|c|c|c|c|c|}
\hline \multicolumn{12}{|c|}{ Collaboration with Korean working groups } \\
\hline & $\begin{array}{c}\mathrm{K}_{\mathrm{RE}} \\
+ \\
\mathrm{K}_{\mathrm{RE}}\end{array}$ & $\begin{array}{c}\mathrm{K}_{\mathrm{RE}} \\
+ \\
\mathrm{K}_{\mathrm{EN}}\end{array}$ & $\begin{array}{c}\mathrm{K}_{\mathrm{RE}} \\
+ \\
\mathrm{K}_{\mathrm{NGO}}\end{array}$ & $\begin{array}{c}\mathrm{K}_{\mathrm{EN}} \\
+ \\
\mathrm{K}_{\mathrm{EN}}\end{array}$ & $\begin{array}{c}\mathrm{K}_{\mathrm{RE}} \\
+ \\
\mathrm{K}_{\mathrm{NGO}} \\
+ \\
\mathrm{K}_{\mathrm{EN}} \\
\end{array}$ & $\begin{array}{c}\mathrm{K}_{\mathrm{ST}}+ \\
\mathrm{K}_{\mathrm{ST}}\end{array}$ & $\begin{array}{l}\mathrm{K}_{\mathrm{NGO}} \\
+\mathrm{K}_{\mathrm{ST}}\end{array}$ & $\begin{array}{c}\mathrm{K}_{\mathrm{NGO}} \\
+ \\
\mathrm{K}_{\mathrm{NGO}}\end{array}$ & $\begin{array}{c}\mathrm{K}_{\mathrm{GOV}} \\
+ \\
\mathrm{K}_{\mathrm{RE}}\end{array}$ & $\begin{array}{c}\mathrm{K}_{\mathrm{GOV}} \\
+ \\
\mathrm{K}_{\mathrm{EN}}\end{array}$ & $\begin{array}{l}\text { Sub } \\
\text { total }\end{array}$ \\
\hline 2017 & 9 & 2 & 2 & 0 & 1 & 1 & 0 & 0 & 0 & 0 & 15 \\
\hline 2018 & 5 & 4 & 0 & 2 & 1 & 0 & 0 & 1 & 1 & 0 & 14 \\
\hline 2019 & 5 & 2 & 1 & 1 & 0 & 1 & 1 & 0 & 0 & 1 & 12 \\
\hline Total & 19 & 8 & 3 & 3 & 2 & 2 & 1 & 1 & 1 & 1 & 41 \\
\hline \multicolumn{8}{|c|}{ Collaboration between Korea and developing countries } & \multicolumn{3}{|c|}{$\begin{array}{c}\text { Collaboration between } \\
\text { working groups }\end{array}$} & USA \\
\hline & $\begin{array}{c}\mathrm{K}_{\mathrm{RE}} \\
+ \\
\mathrm{D}_{\mathrm{RE}} \\
\end{array}$ & $\begin{array}{r}\mathrm{K}_{\mathrm{RE}}+ \\
+\end{array}$ & $\begin{array}{l}\mathrm{K} \\
\mathrm{E}\end{array}$ & $\begin{array}{c}\mathrm{K}_{\mathrm{NGO}} \\
+ \\
\mathrm{D}_{\mathrm{RE}} \\
\end{array}$ & $\begin{array}{c}\mathrm{K}_{\mathrm{NGO}} \\
+ \\
\mathrm{D}_{\mathrm{NGO}} \\
\end{array}$ & $\begin{array}{c}\mathrm{K}_{\mathrm{EN}} \\
+ \\
\mathrm{D}_{\mathrm{NGO}} \\
\end{array}$ & $\begin{array}{l}\text { Sub } \\
\text { total }\end{array}$ & \multicolumn{3}{|c|}{$A_{R E}+A_{E N}$} & $\begin{array}{l}\text { Sub } \\
\text { total }\end{array}$ \\
\hline 2017 & 3 & & & 1 & 1 & 0 & 6 & \multicolumn{3}{|c|}{1} & 1 \\
\hline 2018 & 4 & & & 0 & 0 & 0 & 5 & \multicolumn{3}{|c|}{0} & 0 \\
\hline 2019 & 2 & & & 0 & 0 & 1 & 3 & \multicolumn{3}{|c|}{0} & 0 \\
\hline Total & 9 & & & 1 & 1 & 1 & 14 & \multicolumn{3}{|c|}{1} & 1 \\
\hline
\end{tabular}

지하였다. 나머지 한 건은 미국 내 연구기관과 기업 간의 협 력 연구 내용이었다.

학술활동 과정에서 타 기관 또는 타 국가와 각자의 전문 성이 필요한 융합 분야에서 공동 연구가 발생한다. 적정기 술 분야에 경우에는 개발 도상국 현지 연구 그룹과 국내 연 구 그룹 사이의 협력 연구가 두드러지게 많았으며, 이는 현 지 사정에 밝으면서 연구 분야를 함께 진행하기에 적절한 현지 현구 기관과의 협력을 선호하는 경향을 나타낸다.

또한, 국내 기관들의 협력 연구의 경우, 국내 연구 기관 사이의 협력 연구가 가장 많았으며, 다음으로 국내 연구기 관과 국내 기업간 연구가 많았다.

그 다음으로는 $\mathrm{NGO}$ 가 연구기관과 협력하거나 국내 기업 간 공동 수행한 경우가 많았다. 적정기술학회의 경우 타 학 회의 경우 연구그룹 또는 기업 위주의 발표가 대부분인데 비해, NGO나 정부가 다른 주체와 공동 연구를 바탕으로 학 회 발표를 수행하고 있는 점이 특이점이 있다고 할 수 있다.

향후, 많은 자료가 축적된다면, 주저자/교신저자 분석을 통하여 주요 기여자 분석이 추가되는 경우, 연구에 대한 각 기관별 참여 중요도에 대한 추가 평가가 가능할 것으로 판 단된다.

Table 4와 5의 내용을 종합하여 보면, 물, 의료, 에너지, 교 육뿐 만 아니라 다양한 연구 주제로의 공동연구가 추진되
고 있었으며, 새로운 적정기술 분야의 주제들이 발굴되고 있음을 알 수 있었다. 또한, 일반적으로 학술활동의 주요 참 여자인 연구기관 및 기업뿐 만 아니라 $\mathrm{NGO}$, 정부 등도 공 동 연구에 참여하여 발표를 수행하고 있으며, 그 공동 연구 의 참여 형태도 상당히 다양함을 확인할 수 있었다. 따라서, 앞으로 과학기술ODA 국제컨퍼런스가 지속적으로 성장하 기 위해서는 발표 개수 및 분야가 증가함과 동시에, 적정기 술 분야에서 유효할 수 있는 다양한 협력 형태를 공유하는 장이 될 필요가 있을 것으로 판단된다.

\section{Conclusions}

2017-2019년까지의 적정기술국제학회 발표자료들을 바 탕으로 적정기술국제학회 (ICAT)에서 발표된 연구 동향을 파악하고자 하였다. 발표를 수행한 연구그룹의 공동연구 및 연구 주제에 대한 변화를 계량서지적 방법뿐만 아니라 네트워크 분석 툴을 이용하여 확인해 보았다.

매우 넓고 양한 주제를 가진 적정기술 분야에 대하여 계 량서지적 분석을 적용하는 것이 전반적인 주제 파악 및 발 표자들의 관계에 대한 특성의 일면을 파악할 수 있는 데 활 용할 수 있음을 알 수 있었다. 
다만, 이번 연구 대상 기간이 상대적을 짧고, 연구 주제 가 많아 적정기술 분야 전체에 대한 일반적인 내용까지 도 출하기에는 어려움이 있었다. 이것은 향후 적정기술국제학 회의 연구 발표들이 지속 수행되어 자료가 더 많이 축적되 는 경우, 더 상세한 연구 분석이 가능할 것으로 기대된다. 그리고 각 분야 전문가들을 중심으로 작성된 적정기술 관 련 다수의 리뷰 논문에 포함된 논문들에 대하여 추가적으 로 계량서지적 분석을 수행하는 경우, 상세 분야별 연구 특 성을 파악하거나, 다양한 연구에서 공통적으로 다루고 있 는 요소를 파악하여, 적정기술의 본질 또는 특징을 이해하 는데 도움이 될 수 있을 것으로 예상된다.

\section{References}

Akbari, M., Khodayari, M., Danesh, M., Davari, A., and Padash, H. (2020). A bibliometric study of sustainable technology research, Cogent Business \& Management, 7(1), 1751906.

Bauer, A. M., and Brown, A. (2014). Quantitative assessment of appropriate technology, Procedia Engineering, 78, pp. 345358.
Boakye-Ansah, A. S., Schwartz, K., and Zwarteveen, M. (2020) Aligning stakeholder interests: How 'appropriate' technologies have become the accepted water infrastructure solutions for low-income areas, Utilities Policy, 66, 101081.

Garniati, L., Owen, A., Kruijsen, J., Ishadamy, Y., and Wibisono, I. (2014). Interface between appropriate technology and sustainable energy policy in vulnerable societies, Sustainable Cities and Society, 12, pp. 9-15.

Jeong, S., Cho, I. H., Seok, D., Kim, Y.-S., Moon, J.-H., and Yoon, J. (2018). A study on official development assistance (ODA) in science and technology in Korea, Journal of Appropriate Technology, 4(2), pp. 96-107.

ScienceDirect https://www.sciencedirect.com (February 03, 2021). Shin, H., Hwang, J., and Kim, H. (2019). Appropriate technology for grassroots innovation in developing countries for sustainable development: The case of Laos, Journal of Cleaner Production, 232, pp. 1167-1175.

Zhang, B., Ma, L., and Liu, Z. (2020). Literature trend identification of sustainable technology innovation: a bibliometric study based on co-citation and main path analysis, Sustainability, 12, 8664. 